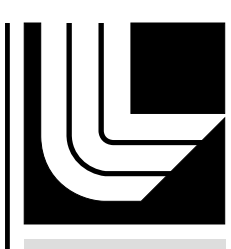

LAWRENCE LIVERM ORE NATIONAL LABORATORY

Modeling Short Shock Pulse Duration Initiation of LX-16 and LX-10 Charges

C. M. May, C. M. Tarver

June 19, 2009

APS Shock Compression of Condensed Matter 2009 Nashville, TN, United States June 28, 2009 through July 3, 2009 
This document was prepared as an account of work sponsored by an agency of the United States government. Neither the United States government nor Lawrence Livermore National Security, LLC, nor any of their employees makes any warranty, expressed or implied, or assumes any legal liability or responsibility for the accuracy, completeness, or usefulness of any information, apparatus, product, or process disclosed, or represents that its use would not infringe privately owned rights. Reference herein to any specific commercial product, process, or service by trade name, trademark, manufacturer, or otherwise does not necessarily constitute or imply its endorsement, recommendation, or favoring by the United States government or Lawrence Livermore National Security, LLC. The views and opinions of authors expressed herein do not necessarily state or reflect those of the United States government or Lawrence Livermore National Security, LLC, and shall not be used for advertising or product endorsement purposes. 


\title{
MODELING SHORT SHOCK PULSE DURATION INITIATION OF LX-16 AND LX-10 CHARGES
}

\author{
Chadd M. May and Craig M. Tarver
}

Lawrence Livermore National Laboratory, Livermore, CA 94550

\begin{abstract}
Very short pulse duration, high pressure shock initiation experiments using electrically driven plastic flyer plates were performed on the explosives LX-10 (95\% HMX, $5 \%$ Viton binder by weight) and LX-16 (96\% PETN, 4\% FPC 461 binder by weight) to measure threshold flyer velocities for detonation initiation. For LX-16, threshold velocities were determined for various flyer materials, thicknesses and diameters. This data was calculated using the Ignition and Growth reactive flow model parameters previously determined for LX-10 and LX-16. Good calculated agreement with experimental threshold velocities was obtained by increasing the maximum fraction ignited during high pressure shock compression compared to the fraction ignited by lower pressure sustained shocks.
\end{abstract}

Keywords: Explosive, LX-10, LX-16, shock to detonation transition, ignition and growth PACS: $82.33 . V x, 82.40 . \mathrm{Fp}$

\section{INTRODUCTION}

Modern detonator systems employ rapid electrical or laser energy deposition into thin metal discs, which vaporize and accelerate small plastic or metal flyer plates into solid explosive charges. The threshold flyer velocities for successful shock initiation of various solid explosives are determined for various explosive and flyer dimensions. Previous electric gun studies used flyer plates whose diameters were much larger than their thicknesses [1]. The shock initiation process was one-dimensional with failure to react being caused by a rarefaction wave from the rear boundary of the flyer plate. Miniaturization has produced small diameter slapper flyer plates, so that the failure to detonate can be caused by either side or rear rarefaction waves. Thus, calculating these experiments requires twodimensional reactive flow modeling. The Ignition and Growth reactive flow model [2] has successfully calculated one-dimensional flyer plate initiation threshold velocities for several solid explosives including: PBX 9404 (94\% HMX, 3\% nitrocellulose, 3\% Chloroethyl phosphate) [2]; LX-17 (92.5\% TATB, $7.5 \%$ Kel-F binder) [3], and Composition B (63\% RDX, 36\% TNT and 1\% wax) [4]. In this paper, the model is applied to one-dimensional initiation data on LX-10 (95\% HMX, 5\% Viton binder) and two-dimensional initiation data on LX-16 (96\% PETN, 4\% FPC 461 binder).

\section{EXPERIMENTAL PROCEDURE}

For the LX-10 threshold tests. printed circuit board technology was used to build slapper flyers that were $4 \mathrm{~mm}$ by $4 \mathrm{~mm}$ with kapton flyer overlays $127 \mu \mathrm{m}$ thick. Since the other two kapton flyer dimensions were much greater than their thicknesses, the shock initiation was one-dimensional. The LX-10 pellets were pressed to a density of $1.85 \mathrm{~g} / \mathrm{cm}^{3}$ 
and were $7.62 \mathrm{~mm}$ diameter by $7.62 \mathrm{~mm}$ high. The measured threshold velocity for initiation was $2.32+/-0.03 \mathrm{~mm} / \mu \mathrm{s}$. For LX-16 initiation, $1.70 \mathrm{~g} / \mathrm{cm}^{3} \mathrm{LX}-16$ pellets $6.35 \mathrm{~mm}$ in diameter by $1.981 \mathrm{~mm}$ high were impacted by $25.4 \mu \mathrm{m}$ thick kapton flyers of five different square dimensions to obtain threshold initiation velocities. These dimensions and measured threshold velocities are listed in Table 1. To measure the effect of flyer thickness at one square flyer size, threshold velocities were measured using $381 \mu \mathrm{m}$ by $381 \mu \mathrm{m}$ ParyleneC flyers with thicknesses ranging from $12 \mu \mathrm{m}$ to $69 \mu \mathrm{m}$. This data is also listed in Table 1.

\section{REACTIVE FLOW MODELING}

The Ignition and Growth reactive flow model [2] uses two Jones-Wilkins-Lee (JWL) equations of state in the form:

$$
p=A e^{-R_{1} V}+B e^{-R_{2} V}+\omega C_{V} T / V
$$

where $\mathrm{p}$ is pressure in Megabars, $\mathrm{V}$ is relative volume, $\mathrm{T}$ is temperature, $\omega$ is the Gruneisen coefficient, $\mathrm{C}_{\mathrm{V}}$ is the average heat capacity, and $\mathrm{A}, \mathrm{B}, \mathrm{R}_{1}$ and $\mathrm{R}_{2}$ are constants. The equations of state are fitted to the available shock Hugoniot and product expansion data. The reaction rate equation is:

$$
\begin{aligned}
& d F / d t=\underbrace{I(1-F)^{b}\left(\rho / \rho_{0}-1-a\right)^{x}}+ \\
& \underbrace{G_{1}}_{0<F<F_{G_{1} \max }} \frac{(1-F)^{c} F^{d} p^{y}}{\left(G_{2}\right.}+\underbrace{G_{2}(1-F)^{e} F^{g} p^{z}}_{F_{G_{2} \min }<F<1}
\end{aligned}
$$

where $\mathrm{F}$ is the fraction reacted, $\mathrm{t}$ is time in $\mu \mathrm{s}, \rho$ is the current density in $\mathrm{g} / \mathrm{cm}^{3}, \rho_{\mathrm{O}}$ is the initial density (calculated based on thermal expansion data), $p$ is pressure in Mbars, and $I, G_{1}, G_{2}$, a, $\mathrm{b}, \mathrm{c}, \mathrm{d}, \mathrm{e}, \mathrm{g}, \mathrm{x}, \mathrm{y}$, and $\mathrm{z}$ are constants. This reaction rate law models the three stages of reaction generally observed during shock initiation of solid explosives. The Ignition and Growth parameters for LX-10 are the same as recently published [5], except that the parameter
Figmax in the first term of Eq. (2) is increased from 0.02 to 0.14 to account for the greater amount of explosive rapidly ignited during shock compression by the very high pressures created by high velocity impacts. Table 2 contains the reaction rate parameters used for LX-16. They are the same as those recently published [6], except that the Figmax, I and $\mathrm{G}_{1}$ parameters are increased to account for faster ignitions and greater amounts of reaction in high pressure, short pulse duration shocks. Table 3 lists the Gruneisen parameters used for the kapton and ParyleneC flyer plate materials.

Table 1. Measured LX-16 threshold velocities.

\begin{tabular}{|c|c|c|c|}
\hline $\begin{array}{l}\text { FLYER } \\
\text { PLATE }\end{array}$ & $\begin{array}{c}\text { IMPACT } \\
\text { VELOCITY } \\
(\mathrm{KM} / \mathrm{S})\end{array}$ & $\begin{array}{c}\text { FLYER SIZE } \\
(\text { MICRONS) }\end{array}$ & $\begin{array}{l}\text { THICKNESS } \\
\text { (MICRONS) }\end{array}$ \\
\hline Kapton & 4.70 & $190.5 \times 190.5$ & 25.4 \\
\hline Kapton & 3.50 & $317.5 \times 317.5$ & 25.4 \\
\hline Kapton & 2.80 & $444.5 \times 444.5$ & 25.4 \\
\hline Kapton & 2.73 & $571.5 \times 571.5$ & 25.4 \\
\hline Kapton & 2.50 & $698.5 \times 698.5$ & 25.4 \\
\hline Parylene & 3.86 & $381.0 \times 381.0$ & 12.3 \\
\hline Parylene & 3.37 & $381.0 \times 381.0$ & 19.6 \\
\hline Parylene & 2.85 & $381.0 \times 381.0$ & 40.8 \\
\hline Parylene & 2.74 & $381.0 \times 381.0$ & 68.6 \\
\hline
\end{tabular}

Table 2. LX-16 reaction rate parameters.

\begin{tabular}{|c|c|}
\hline \multicolumn{2}{|c|}{ MATERIAL PARAMETERS } \\
\hline Shear Modulus $=0.04$ Mbar & $\begin{array}{c}\text { Yield Strength }=0.002 \\
\text { Mbar }\end{array}$ \\
\hline $\mathrm{T}_{\mathrm{O}}=298^{\circ} \mathrm{K}$ & $\rho_{0}=1.70 \mathrm{~g} / \mathrm{cm}^{3}$ \\
\hline \multicolumn{2}{|c|}{ REACTION RATES } \\
\hline $\mathrm{a}=0.0$ & $\mathrm{x}=9.0$ \\
\hline $\mathrm{b}=0.667$ & $\mathrm{y}=1.0$ \\
\hline $\mathrm{c}=0.667$ & $\mathrm{z}=2.0$ \\
\hline $\mathrm{d}=0.04$ & $\mathrm{~F}_{\text {igmax }}=0.10$ \\
\hline $\mathrm{e}=0.667$ & $\mathrm{~F}_{\mathrm{G} 1 \mathrm{max}}=0.04$ \\
\hline $\mathrm{g}=0.667$ & $\mathrm{~F}_{\mathrm{G} 2 \mathrm{~min}^{2}=0.04}$ \\
\hline $\mathrm{I}=220000 \mu \mathrm{s}^{-1}$ & $\mathrm{G}_{1}=55 \mathrm{Mbar}^{-1} \mu \mathrm{s}^{-1}$ \\
\hline- & $\mathrm{G}_{2}=8000 \mathrm{Mbar}^{-2} \mu \mathrm{s}^{-1}$ \\
\hline
\end{tabular}


Table 3. Gruneisen parameters for flyer materials.

\begin{tabular}{|c|c|c|c|c|c|c|c|}
\hline INERT & $\begin{array}{c}\rho_{0} \\
(\mathrm{~g} / \mathrm{cc})\end{array}$ & $\begin{array}{c}\mathrm{C} \\
(\mathrm{km} / \mathrm{s})\end{array}$ & $\mathrm{S}_{1}$ & $\mathrm{~S}_{2}$ & $\mathrm{~S}_{3}$ & $\gamma_{0}$ & $\mathrm{a}$ \\
\hline Kapton & 1.414 & 2.741 & 1.41 & 0.0 & 0.0 & 0.76 & 0.0 \\
\hline $\begin{array}{c}\text { Pary- } \\
\text { leneC }\end{array}$ & 1.286 & 2.228 & 1.37 & 0.0 & 0.0 & 0.76 & 0.0 \\
\hline
\end{tabular}

\section{RESULTS/DISCUSSION}

The failure diameter of LX-10 is between one and two $\mathrm{mm}$ [7] so flyer diameters must be approximately that large to cause shock initiation. The threshold velocity for $2 \mathrm{~mm}$ square, $127 \mu \mathrm{m}$ thick kapton flyers is $2.32+/-$ $0.03 \mathrm{~mm} / \mu \mathrm{s}$. For lower shock pressures, the fraction of explosive ignited during shick compression is approximately equal to the initial void volume, which is $2 \%$ for LX-10 at $1.85 \mathrm{~g} / \mathrm{cm}^{3}$. At the high pressures (well over 10 $\mathrm{GPa}$ ) required for short pulse duration initiation, a greater fraction of the explosive must be rapidly ignited to create enough growing hot spots to cause detonation after the pulse has ended. The run distances to detonation are much longer than those for sustained shocks at the same pressures [4]. The parameter Figmax was varied, keeping the other LX-10 Ignition and Growth parameters based on lower pressure experiments constant. A value of Figmax of 0.14 resulted in a calculated failure to detonate for a $127 \mu \mathrm{m}$ thick kapton flyer at $2.25 \mathrm{~mm} / \mu \mathrm{s}$ and a detonation at $2.50 \mathrm{~mm} / \mu \mathrm{s}$. This fraction ignited is consistent with previous values used to calculate short pulse duration threshold velocities for PBX 9404 and LX-17 [2,3].

The failure diameter of LX-16 is much less than one $\mathrm{mm}$ [7], and therefore flyer plates can correspondingly small if they are driven fast enough. The smallest flyer diameter listed in Table 1 is $190.5 \mu \mathrm{m}$, although smaller diameters have been used. Such small diameter flyers require velocities of $5 \mathrm{~mm} / \mu$ s or more to cause initiation. The shock pressures produced in the LX-16 may even exceed the von Neumann spike pressure of detonating LX-16. These small diameter, very thin flyer 2D threshold velocity experiments on LX-16 are excellent tests for reactive flow modeling.

Table 4 shows the calculated versus experimental threshold velocities for LX-16 in the kapton and ParyleneC flyer experiments listed in Table 1. The parameter Figmax for LX-16 was increased from 0.04 to 0.10 , and the I and $\mathrm{G}_{1}$ coefficients, which cause the first $10 \%$ reaction, were both increased by a factor of 13.75. The calculations were first done for the kapton flyer diameter effect data, and then applied to the ParyleneC flyer thickness data. The calculated threshold velocities agree well with experiment, except for the thinnest ParyleneC flyer. Kapton and ParyleneC have different densities and equations of state. They produce different impact pressures and pulse durations at the same velocity. Kapton produces higher impact pressures, but ParyleneC produces longer pulse durations. The LX-16 reaction rate dependence on pulse duration for Parylene $\mathrm{C}$ flyers requires further study.

The results are also shown graphically in Figs. 1 and 2. Figure 1 contains the experimental and calculated threshold velocities for the different surface area kapton flyers. Figure 2 shows the comparisons for the different thicknesses of ParylreneC flyers.

Table 4. Measured and calculated LX-16 threshold impact velocities.

\begin{tabular}{|l|c|c|c|}
\hline $\begin{array}{l}\text { FLYER } \\
\text { PLATE }\end{array}$ & $\begin{array}{c}\text { THRESHOLD } \\
\text { VELOCITY } \\
(\mathrm{mm} / \mu \mathrm{s})\end{array}$ & $\begin{array}{c}\text { CALCULATED } \\
\text { VELOCITY } \\
(\mathrm{mm} / \mu \mathrm{s})\end{array}$ & $\begin{array}{c}\text { THICK- } \\
\text { NESS } \\
(\mu \mathrm{m})\end{array}$ \\
\hline Kapton & 4.70 & $5.25+/-0.05$ & 25.4 \\
\hline Kapton & 3.50 & $3.35+/-0.05$ & 25.4 \\
\hline Kapton & 2.80 & $2.85+/-0.05$ & 25.4 \\
\hline Kapton & 2.73 & $2.65+/-0.05$ & 25.4 \\
\hline Kapton & 2.50 & $2.55+/-0.05$ & 25.4 \\
\hline ParylC & 3.86 & $5.45+/-0.05$ & 12.3 \\
\hline ParylC & 3.37 & $3.65+/-0.05$ & 19.6 \\
\hline ParylC & 2.85 & $2.65+/-0.05$ & 40.8 \\
\hline ParylC & 2.74 & $2.45+/-0.05$ & 68.6 \\
\hline
\end{tabular}




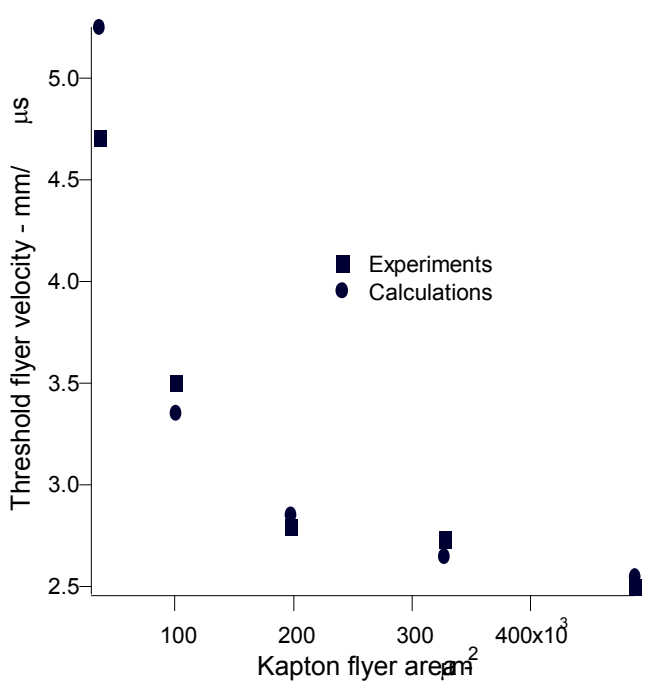

FIGURE 1. Threshold flyer velocity as a function of kapton flyer surface area

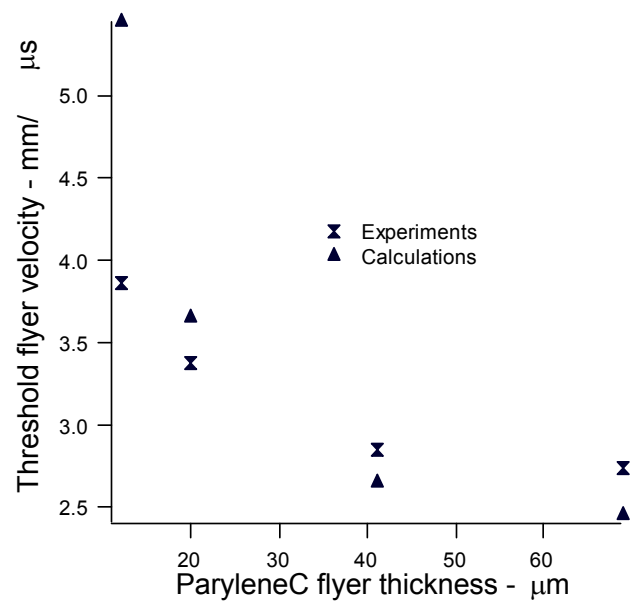

FIGURE 2. Threshold flyer velocity versus ParyleneC flyer thickness

\section{SUMMARY}

Short shock pulse duration initiation experiments on LX-10 and LX-16 are reported. This experimental data is also compared to Ignition and Growth modeling results for the two explosives. Good agreement was obtained for one-dimensional LX-10 initiation and twodimensional LX-16 initiation.

\section{ACKNOWLEDGEMENTS}

Special thanks go to Don Hanson, Roy Hanks and Ralph Hodgin. This work was performed under the auspices of the U. S. Department of Energy by the Lawrence Livermore National Laboratory under ContractDE-AC52-07NA27344.

\section{REFERENCES}

1. Honodel, C. A., Humphrey, J. R., Weingart, R. C., Lee, R. S., and Kramer, P., "Shock Initiation of TATB Formulations," Seventh Symposium (International) on Detonation, Naval Surface Weapons Center NSWC MP 82-334, Annapolis, MD, 1981, pp. 425-434.

2. Tarver, C. M., Hallquist, J. O., and Erickson, L. M., "Modeling Short Pulse Duration Shock Initiation of Solid Explosives," Eighth Symposium (International) on Detonation, Naval Surface Weapons Center NSWC MP 86-194, Albuquerque, NM, 1985, pp. 951-961.

3. Bahl, K., Bloom, G., Erickson, L., Lee, R., Tarver, C., Von Holle, W., and Weingart, R., "Initiation Studies o n L X-17 Explosive," Eighth Symposium (International) on Detonation, Naval Surface Weapons Center NSWC MP 86-194, Albuquerque, NM, 1985, pp. 1045-1056.

4. Urtiew, P. A., Vandersall, K. S., Tarver, C. M., Garcia, F. and Forbes, J. W. "Shock Initiation Experiments and Modeling of Composition B and C4," Thirteenth International Detonation Symposium, Office of Naval Research ONR 351-07-01, Norfolk, VA, 2006, pp. 929-939.

5. Vandersall, K. S., Tarver, C. M., Garcia, F., Urtiew, P. A., and Chidester, S. K., "Shock Initiation Experiments and Modeling on LX-10," Shock Compression of Condensed Matter-2007, AIP Conference Proceedings 955, Waikoloa, HI, 2007, pp. 1010-1013.

6. Tarver, C. M., Lefrancois, A. S., Lee, R. S., and Vandersall, K. S., "Shock Initiation of the PETNBased Explosive LX-16," Thirteenth International Detonation Symposium, Office of Naval Research ONR 351-07-01, Norfolk, VA, 2006, pp. 881-889.

7. Campbell, A. W. and R. Engleke, "The Diameter Effect in High Density Heterogeneous Explosives," Sixth Symposium (International) on Detonation, Office of Naval Research ACR-221, Coronado, CA, 1976, pp. 642-652. 